\title{
A REFERÊNCIA NOS ESTUDOS SEMÂNTICOS
}

\author{
Luiz Francisco Dias \\ Priscila Brasil Gonçalves Lacerda
}

\begin{abstract}
RESUMO
A referência tem sido tratada no âmbito dos estudos semânticos por diversos pontos de vista. Em todos eles, ela se constitui na relação entre um elemento da ordem do linguístico e algo que lhe serve como contraparte. São apresentadas neste artigo algumas concepçóes acerca da natureza da relação referencial com o objetivo de mostrar que é justamente a delimitação da natureza dessa contraparte que determina os contrastes substanciais entre as diferentes perspectivas sobre a referência.
\end{abstract}

PALAVRAS-CHAVE: referência; referenciação; enunciação.

\section{Introdução}

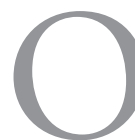

debate sobre a referência ocupa um grande espaço nos campos da semântica, da pragmática e da filosofia da linguagem. E esse debate vai além, rompendo os contornos desses campos, uma vez que alcança a discussão sobre os limites da própria dimensão linguística. A discussão sobre a referência que empreenderemos neste texto tem como eixo exatamente as diferentes concepçôes sobre a relação entre a linguagem e sua exterioridade. $\mathrm{O}$ que estará em discussão são questóes relativas ao gesto referencial. Se eu aponto o meu dedo para uma parede, posso estar me referindo a um quadro, à cor da parede, ao material de que a parede é construída, ao local onde bati a minha cabeça, etc. São as palavras, afinal, que constituem as condiçôes para se "dizer" o referente. A complexidade do debate começa por aqui... 
Os confrontos e divergências teóricas são constitutivos dos estudos linguísticos, e, nos estudos da significação, eles se potencializam. As divergências podem se desenvolver de maneira tão profunda a ponto de suportar o estabelecimento de duas disciplinas diferentes (Semântica e Pragmática), constituídas em torno do mesmo objeto. Efetivamente, as duas disciplinas abordam a significação, mas o fazem de modo bastante distinto, a partir de respostas diferentes para perguntas básicas em torno do campo de estudos do sentido e do significado. Se a natureza da significação como objeto teórico de estudo é controversa, a unidade de análise adotada no interior desse campo apresenta-se ainda mais diversa: enunciado, ato de fala, proposição, frase, texto.

Em meio a essa diversidade, alguns conceitos se destacam como basilares na construção de uma teoria da significação. Dentre eles, destacamos o da referência. Trata-se de um conceito também perpassado pela diversidade de pontos de vista. O presente estudo objetiva mostrar como as diferenças de constituição do campo de estudos da significação refletem no conceito de referência.

Começaremos o nosso texto apresentando a perspectiva de Frege. Em seguida, faremos uma breve revisão das abordagens de Ducrot e de Mondada \& Dubois. Por fim, apresentaremos a perspectiva da semântica da enunciação. Com este texto, pretendemos oferecer uma rota possível de exploração do conceito de referência, a partir de alguns marcos teóricos na história dos estudos da significação. Certamente, estamos ainda muito longe da construção de um quadro definitivo e amplo de abordagem da referência.

\section{Do sentido para a referência}

No final do século XIX, Frege desenvolveu, dentro da perspectiva da lógica, uma diferença que trouxe contribuiçóes fundamentais aos estudos da significação. $\mathrm{O}$ autor tratou da diferença entre sentido e referência, considerando o nome próprio e a sentença.

De acordo com Frege, uma expressão linguística que nomeia algo, i.e., que seja uma designação, apresenta um sentido e uma referência, constituindo assim o que o lógico chamou de nome próprio. $\mathrm{O}$ sentido do nome próprio é definido como "o modo de apresentação do objeto", sendo a sua referência 
o objeto designado por esse nome próprio ${ }^{1}$. A referência do nome próprio é apresentada, portanto, como um objeto pertinente a uma dimensão exterior à linguagem, o que coloca o estudo da referência intrinsecamente situado no encalço dos deslizes ou embates que perpassam essa relação entre a linguagem e o mundo. $\mathrm{O}$ autor mostra-se, então, engajado nesse plano dos deslizes ou embates ao falar sobre a "conexão regular entre o sinal2 ${ }^{2}$, seu sentido e sua referência". Tal conexão deveria funcionar "de tal modo que ao sinal corresponde um sentido determinado e ao sentido, por sua vez, corresponde uma referência determinada". Contudo, no que concerne aos deslizes da relaçáo entre o sinal e o sentido, Frege pondera afirmando que, se as "linguagens naturais não satisfazem a esta exigência", "deve-se ficar satisfeito se a mesma palavra


aos deslizes da relação entre sentido e referência, Frege ajuíza outra questão, ao lembrar que as teorias céticas poderiam mesmo questionar a existência real dos objetos aos quais nos referimos. Contudo, avalia o lógico, a despeito desse questionamento, "quando dizemos 'a lua' [...] pressupomos uma referência"4. Estamos, entretanto, suscetíveis a nos enganarmos sobre a pressuposição de existência por uma questão de inapreensibilidade do real tal como ele é de fato; porém, isso não invalidaria a tese de que a existência do objeto referido foi pressuposta na constituição do nome próprio "a lua".

Frege admite que o "sentido de um nome próprio [...] elucida a referência, caso ele tenha uma, mas de uma maneira sempre parcial"s. Assim, na medida em que o sentido concede-nos apenas uma visão parcial do objeto que se nos apresenta, concede-nos um conhecimento restrito da referência que o nome próprio designa. Segundo a nossa interpretação, esse ponto revela, de forma ainda mais substancial, a discrepância entre a linguagem e o mundo ao qual ela (linguagem) se refere.

1 FREGE, G. "Sobre o sentido e a referência”. In: Lógica e filosofia da linguagem. São Paulo: Cultrix, 1978, p. 63.

2 Para Frege (1978), um sinal seria um nome, uma combinação de palavras ou uma letra, i.e., uma apresentação gráfica (ou sonora) de dimensão variável.

3 Idem, p. 63.

4 Idem, p. 67. Grifo nosso.

5 Idem, p. 63 
Os nomes "o país do futebol”, "o maior país da América Latina”, "o território descoberto por Pedro Álvares Cabral em 1500”, por exemplo, expressam diferentes modos de apresentação, diferentes sentidos para uma mesma referência que podemos localizar no mapa, para um objeto que possui realidade independente no mundo. Cada um desses sentidos dá visibilidade a um conhecimento diverso acerca da referência e elucida uma propriedade específica de um mesmo objeto, também designado pelo nome próprio "Brasil".

Quando Frege diz que o "sentido de um nome próprio [...] elucida a referência, caso ele tenha uma" ${ }^{6}$, podemos depreender que a referência não é algo imprescindível à constituição do nome próprio. Por exemplo, em "o primeiro homem a pisar no solo de Marte", tem-se uma expressão a que se pode atribuir sentido, mas para a qual não encontramos uma referência apreensível entre os humanos.

Como dissemos, Frege também define a relação entre sentido e referência considerando a sentença. Para chegar a tal definição, o autor faz um raciocínio que parte da mencionada pressuposição de existência implicada pelas designaçóes. Segundo Frege ${ }^{7}$, seria razoável imaginar que "todo aquele que não admite que o nome próprio tenha uma referência não lhe pode atribuir nem negar um predicado". Do mesmo modo, seria um contrassenso admitir que a expressão "o homem de Nazaré" tem uma referência e colocá-la como sujeito gramatical de uma sentença como "O homem de Nazaré nunca existiu". Configura-se aquilo que Frege designou de erro lógico, ou "defeito da linguagem", que consiste em se pressupor algo como existente, justamente por se falar dele e, ao mesmo tempo, negar tal existência. Por isso, Frege propõe que é o valor de verdade de uma sentença independente que deve ser a sua referência ${ }^{8}$, entendendo por valor de verdade a circunstância de a sentença ser verdadeira ou falsa; enquanto o "pensamento" seria o seu sentido?. Vejamos a sentença a seguir.

6 Grifo nosso.

7 Idem, p. 68.

8 Aqui falamos apenas do que seria a referência e o sentido de sentenças independentes. Frege (1978) também determinou o sentido e a referência de sentenças que figuram em discurso direto, i.e., sentenças que constituem citação, de sentenças de discurso indireto e de outras subordinadas.

9 Idem, p. 69. 
(1)

O Brasil lança a maior pesquisa do mundo com células-tronco para a cura de problemas cardiológicos. ${ }^{10}$

Frege diria que o sentido da sentença (1) é o pensamento de que o Brasil lança a maior pesquisa do mundo com células-tronco para a cura de problemas cardiológicos. Já a sentença

O maior país católico lança a maior pesquisa do mundo com células-tronco para a cura de problemas cardiológicos

configura um pensamento diferente daquele encontrado em (1), já que conta com a expressão "O maior país católico", no lugar da expressão "Brasil", em sua constituição. E, com efeito, indo além do que Frege nos permite concluir a partir de sua perspectiva lógica, reforçamos por nossa conta a avaliação de que (1) e (2) têm sentidos diferentes, pois a informação segundo a qual o nosso país, apresentado como "O maior país católico", lança uma pesquisa de impacto com células-tronco até constitui um conflito com uma das posições da Igreja, que parece ser contrária a essas pesquisas. Em contrapartida, ambas as sentenças compartilhariam da mesma referência, já que seria atribuído a elas o mesmo valor de verdade ${ }^{11}$.

Pensar no contraste entre as expressóes "Brasil" e "o maior país católico" lembra-nos de que o sentido, por vezes, não garante o acesso à referência - e novamente nos deparamos com a discrepância entra a linguagem e o mundo -, embora Frege postule que o uso da linguagem pressuponha essa referência. Assim, alguém que não tenha o conhecimento de que "o maior país católico" e "Brasil" são modos diferentes de apresentar um mesmo objeto no mundo pode atribuir valores de verdade opostos às sentenças (1) e (2), atribuindo-lhes referências distintas por entender que uma seja verdadeira e outra, falsa ${ }^{12}$.

10 Revista Época, n 351, 7 fev. 2005. p. 4.

11 FREGE, 1978, p. 69.

12 Idem, p. 69. 
Enfim, Frege, considerando os nomes próprios ou as sentenças independentes, define o sentido como diferente da representação, já que esta última resulta de um olhar subjetivo sobre os objetos e verdades ou falsidades do mundo ${ }^{13}$. Queremos ressaltar que, tendo como referência um objeto, o sentido, além de ser uma apresentação objetiva da referência, consiste em uma apresentação unilateral dessa referência, e por isso incapaz de apreendê-la em sua completude. Para chegar a essa constatação, Frege teve de tomar a referência em sua natureza exterior à linguagem para delinear a natureza restrita do sentido. Em outras palavras, Frege, ao lançar os objetos como referência, não os perde de vista em sua completude, em sua diversidade de aspectos, tal como eles seriam no mundo. Assim, o autor apresenta o sentido como uma lente de telescópico que apenas pode vislumbrar o objeto focalizando-o por um ângulo específico, iluminando uma de suas propriedades, mas jamais o atingindo por completo. Segundo a perspectiva de Frege, a referência tem uma abrangência que escapa aos limites do sentido que a apresenta. E o sentido, por sua vez, é limitado porque só alcança parcialmente a referência que, articulado a ele, constitui o nome próprio. Da mesma forma, no caso das sentenças independentes, o valor de verdade tem como parâmetro a exterioridade linguística, que naturalmente excede o pensamento.

\section{A construção do referente}

Ducrot ${ }^{14}$ seguindo outra direção, aborda a referência considerando uma distinção entre o referente e o que poderíamos chamar de realidade. Para esse autor, a referência se dá como um processo de constituição do referente. Nesse processo, há uma orientação daquilo que se diz para aquilo que não é o dizer. O confronto do linguístico com uma realidade exterior e independente à palavra, segundo Ducrot, faz-se necessário no processo referencial. Há uma "tendência da palavra para valer fora dela própria" afirma Ducrot ${ }^{15}$. Vejamos novamente a sentença em (1), agora acrescida de outra sentença que, no texto publicitário, a antecede.

13 Idem, p. 66.

14 DUCROT, O. Referente. In: Enciclopédia Einaudi. v.2. Lisboa: Imprensa Nacional - Casa da Moeda, 1984.

15 DUCROT, 1984, p. 436. 
(1a)

Bata no peito com orgulho. O Brasil lança a maior pesquisa do mundo com células-tronco para a cura de problemas cardiológicos. ${ }^{16}$

Em (1a), apresentamos parte de um texto publicitário do Ministério da Saúde veiculado em uma revista de circulação nacional que descreve um país que investe em pesquisa de ponta na área de saúde e, por isso, merece que a nação tenha orgulho dele. Em contrapartida, se tivéssemos o enunciado

Bata no peito com orgulho. O Brasil conquista uma vaga para disputar o campeonato de futebol nas Olimpíadas de 2008.

estaríamos diante da descrição de um país que merece o orgulho de sua população porque está bem representado no futebol. Comparando-se (1a) e (1b), percebemos que o primeiro, publicado na revista Época, respalda-se em um discurso que valoriza o desenvolvimento de pesquisas em favor da saúde humana e, portanto, considera o investimento do Estado em pesquisas de ponta na área de saúde como algo positivo. Por outro lado, o segundo texto ancora-se em um discurso que valoriza o esporte e, portanto, considera um mérito a conquista esportiva. Podemos afirmar que cada um desses textos descreve o Brasil de acordo com o discurso que os norteia e, portanto, constituem referentes distintos. Segundo a perspectiva de Ducrot, o Brasil que cuida da saúde e o Brasil do futebol são referentes que estão inscritos, cada qual, no discurso que os criou.

Sendo o referente uma criação discursiva, o enunciado "O homem de Narazé nunca existiu" não seria um problema para Ducrot. O referente de "O homem de Nazaré", independentemente de nossas crenças ou religióes, ganha existência num discurso. Nesse caso, a alusão à realidade estaria justamente no dizer da inexistência, ou seja, ainda fazemos alusão à realidade ao dizermos que algo não se encontra nela. A realidade ganharia pertinência justamente no gesto de se apontar para ela.

$\overline{16}$ Revista Época, n 351, 7 fev. 2005, p. 7. 
Instala-se, então, "o estatuto ambíguo do referente"17, que se apresenta como uma alusão à realidade, pois isso é próprio da natureza do discurso humano, mas, na verdade, é uma realidade instituída pelo discurso. Poderíamos comparar o referente, no que diz respeito a sua ambiguidade, a uma pintura figurativa, cujo desenho orienta-se para o exterior que representa, almejando ser um espelho dessa exterioridade, mas constitui-se como uma diferença inexorável desse exterior, advinda do fato de ser uma criação artística e não a própria realidade.

Poderíamos garantir a exterioridade do referente levando em conta o fato de outros discursos também o visarem ${ }^{18}$, isto é, considerando que o "objeto tem a sua objetividade constituída pelo fato de várias falas falarem deste objeto" ${ }^{19}$. Por exemplo, nos discursos de valorização do desenvolvimento de pesquisas em favor da saúde e dos benefícios da competição esportiva - textos (1a) e (1b) - reconhecemos que eles visam um referente comum, o "Brasil", que merece ser motivo de orgulho da sua população. Por outro lado, eles o descrevem cada qual a partir de sua ancoragem discursiva e, portanto, descrevem-no diferentemente. Em outras palavras, o objeto, na condição de exterioridade, é constituído de algum modo pela linguagem.

Em formulação mais recente, Ducrot afirma: "não nos perguntamos o que se passa na realidade quando alguém tem pressa, mas que discursos podem dar-se lugar frente à indicação de que alguém tem pressa" ${ }^{20}$. O sentido de ter pressa advém da sua associação com agir rapidamente. Sendo agir rapidamente uma entidade do discurso, o doador de sentido é o discurso. Dessa maneira, o sentido de uma entidade linguística advém da evocação ou modificação de discursos, o que equivale a dizer que o sentido é construído no encadeamento discursivo.

\section{Da referência para a referenciação}

Mondada e Dubois (2003), por sua vez, consideram a referência como "produzida pelos sistemas cognitivos humanos, utilizando uma ampla varie-

17 DUCROT, 1984, p. 419.

18 DUCROT, 1984, p. 420.

19 GUIMARÁES, E. Os limites do sentido. 3. ed. Campinas: Pontes, 1995, p. 73, revisando DUCROT, 1984.

20 DUCROT, O. Os internalizadores. Letras de Hoje. Porto Alegre, v. 37, n. 3, 2002, p. 9. 
dade de dispositivos e de restrições, aqueles das línguas naturais" ${ }^{21}$. Elas afirmam que a "referenciação" não é um problema ontológico, e se constitui por um "trabalho de interpretação". Ou seja, o mundo não se encontra discreto, estabelecido a priori. Antes, tudo o que vislumbramos como entidades distinguíveis umas das outras na exterioridade linguística são configuradas por perspectivas constituídas na discursividade. Assim, retomando as categorias "o país do futebol”, "o maior país católico" e "o território descoberto por Pedro Álvares Cabral em 1500”, já apontadas anteriormente, podemos verificar que cada uma dessas categorias arregimenta uma perspectiva de concepção do país. Nesse sentido, o termo "referenciação" tornar-se-ia mais adequado do que "referência", por se relacionar com um processo de construção interpretativa. Em relação à abordagem de Frege, saem de cena a noção de valor de verdade e a concepção de entidade externa e independente da discursividade.

No escopo dessa abordagem, o fato de a "referenciação" estar vinculada a práticas simbólicas contorna o problema lógico que seria encontrado por Frege na sentença "O homem de Nazaré nunca existiu”, uma vez que a categoria "o homem de Nazaré" não emerge de uma ontologia prévia.

Ainda segundo Mondada e Dubois, as categorias guardam uma instabilidade constitutiva. Tal instabilidade relaciona-se com o que as autoras chamaram "indicialidade da linguagem e do discurso" e confere às categorias da linguagem uma dependência contextual ${ }^{22}$. Resumindo, a "instabilidade das categorias está ligada a suas ocorrências" 23 . Isto significa que as categorias estão submetidas a um processo adaptativo de ajuste ao contexto. Ilustremos essa abordagem, observando a seguir o trecho de um artigo sobre a colocaçáo do Brasil na medida do Índice de Desenvolvimento Humano (IDH), publicado no Jornal de Brasilia em julho de 2004.

[...] na 55a posição (IDH 0,797), [...] está o gigante adormecido de Pindorama, terra do pau-brasil, nação

${ }^{21}$ MONDADA, L; DUBOIS, D. Construção dos objetos de discurso e categorização: Uma abordagem dos processos de referenciaçáo. In: CAVALCANTE, M; RODRIGUES, B; CIULLA, A. (orgs.). Referenciação. São Paulo: Contexto, 2003, p. 49.

22 MONDADA e DUBOIS, 2003, p. 40.

${ }^{23}$ MONDADA e DUBOIS, 2003, p. 29. 
continental com 8,51 milhões de quilômetros quadrados de área, onde se distribuem 180 milhóes de, na sua maioria, sofridas almas. O País do futebol, das mulatas e do Carnaval, com seu potencial industrial, comercial e agrícola, registra aos brasileiros uma renda per capita de US\$ 2,83 mil, que mascara a expressiva concentração de renda. Apesar de grande exportador de manufaturados e produtos agropecuários, ainda estão evidentes os índices alarmantes de desigualdade social. Há mais de 11 milhôes de famílias abaixo da linha da pobreza - com renda de US\$ 2 por dia. ("Entre a Noruega e o Quirguistão”, artigo de Vilson Antonio Romero) [Destaques nossos.].

As categorias levantadas nesse trecho apresentam o Brasil em sua grandiosidade, destacando traços de sua história e suas proeminências culturais. Tais categorias, figurando em outros discursos, constroem outros objetos discursivos. A categoria "O País do futebol, das mulatas e do Carnaval" integraria um discurso acerca do Brasil exaltando, por exemplo, a receptividade e a alegria que caracterizam, de modo geral, os brasileiros aos olhos dos estrangeiros. No excerto transcrito em (3), porém, essa categoria, articulada com as outras categorias destacadas, está engajada na construção colaborativa de um objeto de discurso específico. A articulação dessas categorias constitui como objeto de discurso um país em que a desigualdade social impera, um país onde a grandiosidade, as riquezas naturais e culturais não significam qualidade de vida para a sua população. É nesse sentido, portanto, que as categorias são instáveis. A categoria "O País do futebol, das mulatas e do Carnaval" ora poderia constituir, como objeto de discurso, um Brasil cujas características de sua popularidade são exaltadas, ora contribui para a constituição, como objeto de discurso, de um país que se encontra na $55^{a}$ posição no ranking mundial do IDH.

Dessa maneira, Mondada e Dubois pretendem defender a tese segundo a qual o trabalho de interpretação é essencial no tratamento da referenciação, dada a instabilidade das categorias constituídas no discurso. 


\section{A referência e a relação entre memória e atualidade}

Por fim, apresentamos a questão da referência sob uma perspectiva enunciativa. Para essa abordagem, "a constituiçâo da referência não é algo da relação entre a linguagem e o real" 24 , como defendia Frege, ao focalizar o debate sobre a referência no modo de localizar e distinguir, no mundo, os objetos referidos pelos nomes próprios e os parâmetros para se estabelecer o valor de verdade das sentenças independentes. Para uma semântica da enunciação, "a referência se constitui na relação entre o acontecimento do dizer e o domínio histórico da constituição desse acontecimento"25. Faz-se necessário, então, esclarecer como se dá o acontecimento enunciativo.

Essa perspectiva de semântica considera a enunciaçáa como um acontecimento caracterizado pela relaçáo entre um enunciado atual e enunciados anteriores, uma relação entre atualidade e memória, portanto. Por sua vez, um enunciado atual já suporta uma latência de futuro e será suporte para o corpo memorável de outras enunciaçóes ${ }^{26}$. A referência, ao se configurar como relação entre a linguagem e um objeto no mundo, o faz sendo mediada por um efeito de sentidos atribuídos por essa relaçáo entre enunciados. Vejamos o enunciado a seguir, que compóe a propaganda de uma instituição financeira.

Aposentados e pensionistas do INSS têm BB Crédito Benefício. $^{27}$

A expressão "aposentados e pensionistas do INSS" constitui referência tendo em vista uma memória de sentidos constituída pelas enunciaçôes políticas, sociológicas e jurídicas que instituem a categoria social de aposentados e de pensionistas do INSS e que intervêm na atualidade da enunciação de (5). Sustentada por esse histórico de enunciaçôes que deram sentido e pertinên-

${ }^{24}$ DIAS, L. F. Problemas e desafios na constituição do campo de estudos da transitividade verbal. In: MARINHO, J.H.C., SARAIVA, M.E.F. (Orgs.). Estudos da língua em uso. Belo Horizonte: Faculdade de Letras/UFMG, 2005, p.119.

25 DIAS, 2005, p. 119.

26 GUIMARÁES, E. Semântica do acontecimento. Campinas: Pontes, 2002.

27 Época, n 351, 7 fev. 2005. p. 38. 
cia social ao grupo de pessoas que passaram a ser designadas "aposentados" e "pensionistas", essa expressão faz sentido e, dessa forma, se refere a um grupo de pessoas dentro da sociedade. Há referência numa enunciação porque há relaçôes de sentido com outras enunciaçóes, produzindo como efeito a pertinência e o reconhecimento dos objetos referidos, os quais são, na verdade, entidades históricas. Não existiriam as entidades designadas por "aposentado" e "pensionista" se não houvesse a constituição histórica das categorias de aposentado e pensionista. Para melhor compreendermos como se dá a constituição da referência no acontecimento enunciativo, observemos o esquema a seguir.

Figura 1. Constituição da referência na semântica da enunciação

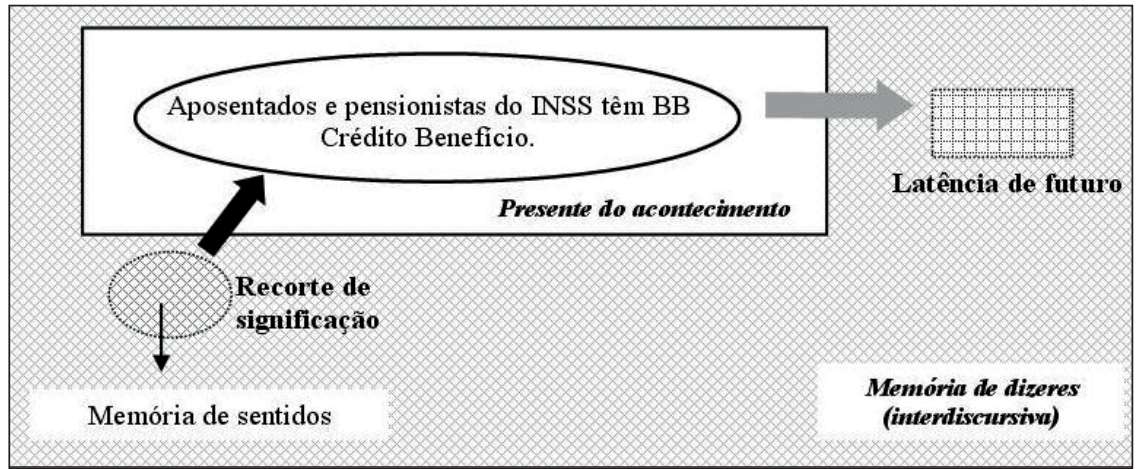

As expressóes que constituem referência se articulam no arranjo sintático do enunciado em que se inscrevem. A referência, assim, se constitui na interface entre o recorte de significação que delimita a memória de sentidos na condição de unidade linguística e a atualidade do acontecimento de dizer, que tem identidade no presente da enunciação como fragmento de texto publicitário. No presente desse acontecimento imerso na publicidade, o "BB Crédito Benefício" se configura como algo de interesse para o consumidor, uma vez que há uma articulação com o recorte de significação inscrito em "aposentados e pensionistas do INSS”, que guarda uma memória de dizeres que identifica aposentados e pensionistas do INSS como uma categoria economicamente desprivilegiada.

Dessa forma, podemos dizer que as unidades linguísticas que produzem referência, ao se articularem no interior do enunciado, configuram mutuamente a referência que produzem. Observemos mais um exemplo: 
(6)

O Brasil tem uma distribuição da renda desigual. ${ }^{28}$

As unidades que constituem referência, a saber, "Brasil" e "uma distribuição da renda desigual”, articulam-se na composição do enunciado e, ao fazê-lo, produzem as condiçóes para um enfoque mais ou menos determinado na memória de sentidos que perpassa a materialidade linguística dessas unidades. "O Brasil", por exemplo, é perpassado por uma memória de sentidos que se entrecruzam, produzindo a sua referência. $\mathrm{Na}$ composição do enunciado em (6), temos um enfoque sobre o aspecto social e econômico do país, enfoque esse que configura a referência produzida por "Brasil" nesse enunciado, pois o constrói como país da desigualdade e talvez da injustiça. Como os sentidos que perpassam a materialidade linguística de "Brasil" se apresentam entrecruzados, outros sentidos inscritos nesse elemento linguístico também se instalam na constituição do enunciado em (6). Apenas temos um foco sobre o sentido da desigualdade e da injustiça que configura a sua referência no enunciado em questão, porém, isso não nega o fato de a constituição referencial do elemento linguístico "Brasil” também agregar outros sentidos, sendo necessário admitirmos que eles permanecem em estado latente.

A configuração da referência, que se dá a partir da articulação dos elementos no enunciado, constituirá, por sua vez, o que Guimarães ${ }^{29}$ chamou de latência de futuro. Os sentidos mudam, e a referência muda, justamente porque a atualidade do acontecimento é capaz de agregar novas perspectivas aos recortes de memória, projetando diferenças para os acontecimentos posteriores.

Como dissemos, os recortes de constituição de referência são realizados a partir do lugar social ocupado pelo sujeito da enunciação. No caso da propaganda da instituição financeira, por exemplo, temos o locutor-bancário, ao passo que para o enunciado em (6) temos possivelmente o locutor-cidadão ou o locutor-analista do desenvolvimento humano mundial. Esse sujeito, locutor que fala a partir de um lugar social, é afetado por esquecimentos que o fazem acreditar que o seu dizer reflete "a realidade ou um sistema de evidências

28 http://noticias.terra.com.br/brasil/interna/0,,OI343300-EI306,00.html, 18/01/2007.

29 GUIMARÃES, E. Semântica do acontecimento. Campinas: Pontes, 2002. 
'em si'”30. O locutor, então, assume o lugar de dizer enquanto enunciador, eximindo-se do lugar social a que pertence. Dessa forma, podemos constatar que a cena enunciativa coloca em jogo lugares sociais do locutor, de um lado, e lugares de dizer, chamados de enunciadores, de outro ${ }^{31}$.

Enfim, podemos afirmar que, para essa concepção enunciativa, a referência se constitui na relação entre a atualidade do dizer, na qual se estabelecem as articulações e se representam os enunciadores, e o domínio histórico desse dizer, que é resgatado pelos recortes na rede interdiscursiva realizados por um locutor a partir de seu lugar sócio-histórico. Assim, de acordo com essa concepção, podemos dizer que a expressão "O homem de Nazaré”, que constitui o enunciado "O homem de Nazaré nunca existiu”, é perpassada por uma memória de sentidos que constitui a sua referência. Essa referência é configurada no âmbito do enunciado em acontecimento por meio da declaração atual de sua inexistência, revelando um locutor que fala possivelmente do lugar social do ateísmo, mas se representa como um enunciador-universal, já que a sua fala se apresenta sem as marcas da individualidade, como se fosse a expressão de uma verdade, independentemente da perspectiva do locutor.

\section{Considerações finais}

Pretendíamos, neste texto, apresentar algumas abordagens da referência seguindo percursos teóricos definidos. Iniciamos com Frege, que centra o debate sobre a referência no modo de localizar e distinguir um objeto referido, e passamos por Ducrot, que concebe a referência como elemento da ordem da discursividade. Além disso, vimos a proposta de Mondana e Dubois, para quem a referência passa por uma categorização linguística com pouca estabilidade semântica, que vai ganhando contornos nos usos da linguagem. Finalmente, apresentamos a perspectiva da semântica da enunciação, que concebe a referência como uma relação entre os recortes históricos de sentido que tornam uma entidade pertinente num acontecimento, produzindo o efeito de evidência dos referentes.

Podemos constatar que nenhuma das propostas de abordagem posterio-

30 CARDOSO, S. H. B. A questão da referência. Campinas: Autores Associados, 2003, p. 136.

31 GUIMARÃES, 2002, p. 26. 
res a Frege negam o efeito de apontamento para algo exterior à linguagem, inerente à referência. O que elas ressaltam nesse aspecto é que o gesto de apontamento é determinante para se conceber as entidades dessa exterioridade. Esse gesto, afinal, é um gesto de linguagem, amalgamado por discursividades, apreendido por um acontecimento, orientado por perspectivas sócio-históricas, etc. É nesse ponto que reside um dos mais intrigantes lances do debate sobre a referência nos estudos semânticos.

\title{
THE REFERENCE IN SEMANTIC STUDIES
}

\begin{abstract}
The reference has been treated in semantic studies through many approaches. All these approaches conceive it in a relation between an element belonging to the linguistic order and something that works as its counterpart. Some perspectives concerning the nature of referential relation are presented in this paper, which aims to show that it is the nature of the counterpart that determines the substantial contrasts among the different views regarding reference.
\end{abstract}

KEYWORDS: reference; referentiation; enunciation.

Recebido em: 25/03/2013

Aprovado em: 26/08/2013 